\title{
Ghrelin PYY 3-36 Serum Changes in Left Ventricular Hypertrophic, Insulin-Resistant, Hypertensive Obese Patients
}

\author{
Iwona Karcz-Socha ${ }^{a}$ Krystyna Zwirska-Korczala ${ }^{a}$ Marian Zembala ${ }^{b}$ Halina Borgiel-Marek ${ }^{c}$ \\ W. Konrad Karcz ${ }^{d}$ \\ ${ }^{\text {a }}$ Department of Physiology, \\ ${ }^{\mathrm{b}}$ Department of Cardiac Surgery and Transplantation, Silesian Center for Heart Diseases, Medical University of Silesia, Zabrze, \\ ${ }^{\circ}$ Department of Maxillofacial Surgery, Medical University of Silesia, Katowice, Poland \\ ${ }^{\mathrm{d}}$ Department of Abdominal Surgery, University of Freiburg, Germany
}

\section{Keywords}

Ghrelin · PYY 3-36 · Hypertension .

Left ventricular hypertrophy $\cdot$ Insulin resistance $\cdot$ Obesity

\section{Summary}

Aim: Hypertension is a major health problem and is usually associated with common conditions such as obesity, which contribute to clinical cardiac dysfunction. The role of energy homeostasis hormones such as ghrelin and PYY 3-36 in cardiovascular function remains incompletely understood. Therefore, the aim of our study was to explore the potential differences in concentrations of ghrelin forms and PYY 3-36 circulating in obese patients with grade 1 and grade 2 hypertension, with higher and lower BMI and without and with insulin resistance as well as to determine whether these hormones may be associated with left ventricular hypertrophy. Methods: A total of 142 adult subjects were studied in three subgroups: lean (BMI $<25 \mathrm{~kg} / \mathrm{m}^{2}$ ) normotensive subjects and obese subjects (BMI 30.0-34.9 $\mathrm{kg} / \mathrm{m}^{2}$ ), and obese subjects (BMI $35.0-39.9 \mathrm{~kg} / \mathrm{m}^{2}$ ) under hypertensive treatment for at least 9 years. Fasting blood glucose, insulin, highsensitivity C-reactive protein (hs-CRP), lipid profile, urinic acid, acylated ghrelin (A-Ghr), total ghrelin (T-Ghr), and PYY 3-36 were measured. Insulin resistance was determined by the homeostasis model assessment of insulin resistance (HOMA-IR). We also echocardiographically assessed left ventricular mass (LVM) index (LVMI = LVM/ height $\left.^{2.7}\right)$. We evaluated the association between plasma T-Ghr, A-Ghr, PYY 3-36 levels with LVMI and other measured factors using univariate and multivariate analysis.
Results: There were significant differences between BMI, waist circumference (WC), LVMI, hs-CRP and A-Ghr/nonacylated ghrelin (NA-Ghr) ratio (in the two obese subgroups. There was no significant difference between T-Ghr, A-Ghr and PYY 3-36 levels between obese subgroups. T-Ghr and PYY 3-36 were significantly lower in obese patients than in the control group, whereas A-Ghr levels did not differ between obese and controls. A-Ghr/ NA-Ghr ratio was significantly higher in patients with second-degree hypertension and BMI 35.0-39.9 kg/m² than in patients with first-degree hypertension and BMI $30.0-34.9 \mathrm{~kg} / \mathrm{m}^{2}$. There were negative associations between T-Ghr, NA-Ghr or PYY 3-36 and LVMI ( $r=-0.49$, $p=0.0001 ; r=-0.47, p=0.0001$; or $r=-0.18, p=0.029$, respectively) and positive association between $A-G h r /$ NA-Ghr ratio and LVMI ( $r=0.3, p=0.0003)$. T-Ghr and NA-Ghr, were associated negatively with fasting insulin $(r=-0.31, p=0.0025 ;$ and $r=-0.36, p=0.001$, repectively), while A-Ghr/NA-Ghr ratio was positively associated with BMI and fasting insulin $(r=0.23, p=0.041$; $r=0.3, p=0.0045$, respectively). T-Ghr, A-Ghr, and NAGhr were also inversely related to HOMA-IR indices in obese patients $(r=-0.43, p=0.001 ; r=-0.32, p=0.0359$; $r=-0.35, p=0.001$, respectively). In insulin-resistant obese subjects T-Ghr and NA-Ghr correlated negatively with HOMA-IR ( $r=-0.34, p=0.0015 ; r=-0.28, p=0.0116$, respectively). LVMI was associated negatively with T-Ghr, NA-Ghr and PYY 3-36 ( $r=-0.49, p=0.0001$; $r=-0.47, p=0.0001 ; r=-0.18, p=0.029$, respectively). In addition, LVMI was positively associated with A-Ghr/ NA-Ghr ratio ( $r=0.30, p=0.0003)$. Conclusion: Plasma

\section{KARGER \\ Fax +497614520714 \\ Information@Karger.de}

www.karger.com (c) 2011 S. Karger GmbH, Freiburg

$1662-4025 / 11 / 0045-0386 \$ 38.00 / 0$

Accessible online at:

www.karger.com/ofa
Dr. W. Konrad Karcz

Abteilung Allgemein- und Viszeralchirurgie mit Poliklinik

Chirurgische Universitätklinik

Hugstetter Straße 55, 79106 Freiburg, Germany

konrad.karcz@uniklinik-freiburg.de 
ghrelin forms and PYY 3-36 levels are associated with LVMI. These associations indicate a possible interaction between gut peptides and the cardiovascular system in hypertension and obesity.

\section{Introduction}

Obesity is recognized as an independent risk factor for cardiovascular diseases and is strongly associated with hypertension, insulin resistance and other cluster features associated with metabolic syndrome [1]. Data suggest that left ventricular hypertrophy is an independent risk factor for cardiovascular morbidity and mortality in the general population while hypertension and obesity are principal determinants among lifestyle factors [2]. However, the pathophysiology of cardiovascular manifestation in obesity is unclear. Subjects with simple obesity show anatomic and hemodynamic abnormalities due to excess weight, including increased left and right ventricular mass and increased left and right end-diastolic volume [3]. Moreover, hypertensive nonobese patients show concentric left ventricular hypertrophy due to increased afterload, whereas obese individuals, even the normotensive, show eccentric left ventricular hypertrophy due to increased preload [4, 5]. Hypertensive obese patients may present both mechanisms.

Ghrelin is abundantly secreted primarily from X/A cells of the oxyntic glands in the mucosa layer of the fundus of the stomach [6]. There are two major forms of ghrelin present in plasma: acylated, with n-noctanoyl ester at its third serine residue, (A-Ghr) and desacyl-ghrelin (NA-Ghr). The latter is a predominant form in blood and represents $79-86 \%$ of total ghrelin (T-Ghr) [7]. PYY 3-36 is another peptide hormone in circulation, secreted by endocrine ileal and colonic L-cells [8]. These two peptides have opposite effects on satiety and also on some known peripheral effects such as arterial pressure [9]. Intravenous infusion of ghrelin acutely lowers blood pressure in both humans [10] and rats [11] while evidence from animal studies suggests that PYY 3-36 affects hypertension [12]. The exogenous forms of both A-Ghr and NA-Ghr are also able to reduce ET1-dependent vasoconstriction and to improve NO bioavailability in the vessels of patients with MetS [13,14]. Ghrelin exerts a protective role against atherosclerosis by antiinflammatory [15-17], antioxidant effects [18] as well as through improved endothelial function $[19,20]$. It has been shown that low plasma ghrelin levels are associated with obesity [21], hypertension [22, 23], insulin resistance [24] and metabolic syndrome [25]. These findings indicate that the gastrointestinal peptides may affect cardiovascular function. To our knowledge, the association between cardiac abnormalities, ghrelin and PYY 3-36 in hypertensive obese subjects has not been reported yet. Therefore the aim of our study was to explore the potential differences in concentrations of ghrelin forms and PYY 3-36 circulating in hypertensive obese patients with higher and lower degrees of hypertension, with higher and lower BMI and without and with insulin resistance as well as to determine whether these hormones may be associated with left ventricular hypertrophy.

\section{Participants and Methods}

\section{Subjects}

The groups were recruited from eligible patients consecutively reporting to the cardiac clinic with hypertension and obesity (BMI above $30 \mathrm{~kg} / \mathrm{m}^{2}$ and below $\left.39.9 \mathrm{~kg} / \mathrm{m}^{2}\right)$, postmenopausal women $(\mathrm{n}=48)$ and age-matched men $(\mathrm{n}=48)$. The control group consisted of eligible healthy subjects $(\mathrm{n}=46)$. All the subjects underwent pre-study screening by standard physical examination including oral cavity routine clinical laboratory tests, including liver and kidney function tests, lipid profile, chest X-ray and baseline ECG. The exclusion criteria were as follows: coronary artery diseases (history of revascularization), ischemic ST segment alterations, valvular heart diseases, arrhythmias, secondary causes of hypertension or obesity-related diabetes mellitus, hepatic and renal or mental diseases, hypothyroidism, and no history of alcohol consumption. Written consent was obtained from every subject, and the study protocol was approved by the Institutional Ethics Committee (Medical University of Silesia, Katowice, Poland). The patients included in the examination had not been treated with aspirin, estrogens, and statins through 5 drug half-lives preceding the beginning of the examination. Antihypertensive drugs which were administered included ACE inhibitors (83\%), angiotensin II receptor blockers $(13.7 \%), \mathrm{Ca}^{2+}$ channel blockers (77\%), adrenergic $\beta$-blockers (69\%), and diuretics (59\%).

\section{Anthropometric and Clinical Data}

Anthropometric measurements included standing height, weight, BMI, and waist circumference (WC). Systolic blood pressure (SBP) and diastolic blood pressure (DBP) were measured in the seated position after a 15-min rest, using a standard mercury sphygmomanometer (DBP; Korotkoff phase V). Blood pressure was averaged by 3 different measurements. According to the Joint National Committee (JNC VII) criteria, patients with SBP 140-159 mm Hg and/or DBP 90-99 mm Hg were assigned to the group with hypertension grade 1 , whereas patients with SBP 160-179 $\mathrm{mm} \mathrm{Hg}$ and/or DBP $100-109 \mathrm{~mm} \mathrm{Hg}$ were assigned to the group with hypertension grade 2 [26].

\section{Laboratory Data}

Blood samples were taken from each subject after a 12-hour overnight fast. Glucose, total cholesterol, high-density lipoprotein (HDL) cholesterol, triglycerides, uric acid, fibrinogen, AST/GOT, ALT/GPT, and TSH levels were measured using autoanalyzer SYNCHRON CXS (Beckman Coulter, Krefeld, Germany). High-sensitivity C-reactive protein (hsCRP) was measured by immunoturbidimetric assay (Roche Diagnostics, Mannheim, Germany). The next samples were collected to the chilled tubes containing $1.2 \mathrm{mg}$ EDTA and aprotinin $(500 \mathrm{KIU} / \mathrm{ml}$; Trasylol; Bayer, Leverkusen, Germany) for hormone analyses. All samples were kept in an ice bath until centrifugation at 2,000 rpm for $15 \mathrm{~min}$ at $4{ }^{\circ} \mathrm{C}$. Additionally, plasma for both total and A-Ghr and PYY 3-36 was collected according to laboratory recommendations using $\mathrm{HCl}, \mathrm{PMSF}$, and DPPIV inhibitor. The separated plasma samples were stored at $-70{ }^{\circ} \mathrm{C}$ until the time of the assay. All samples of one subject were run in duplicate in the same radioimmunoassay (RIA) performed in the laboratory of Silesian Medical University (Isotopic Laboratory of Department Pathophysiology, Zabrze, Poland). Plasma T-Ghr, A-Ghr, and PYY 3-36 were measured using commercial RIA kits (Linco Research, St. Charles, MO, USA); inter-assay or intra-assay coefficients of variations for T-Ghr, A-Ghr and PYY $3-36$ were $7.0 \%$ or $14.3 \% ; 3.3 \%$ or $17.8 \%$ and $11 \%$ or 
Table 1. Antropometric and metabolic characteristic of the entire study population and healthy control ${ }^{\mathrm{a}}$

\begin{tabular}{|c|c|c|c|}
\hline \multirow[t]{2}{*}{ Variables } & \multirow{2}{*}{$\begin{array}{l}\text { Lean } \\
\text { BMI }<25.0\end{array}$} & \multicolumn{2}{|l|}{ Obese } \\
\hline & & BMI 30.0-34.9 & BMI 35.0-39.9 \\
\hline Number & 46 & 43 & 53 \\
\hline Females/males & $24 / 22$ & $22 / 21$ & $26 / 27$ \\
\hline Age, years & $51.2 \pm 6.5$ & $50.5 \pm 6.2$ & $52.3 \pm 6.6$ \\
\hline Height, $\mathrm{cm}$ & $169.6 \pm 7.5$ & $165.4 \pm 9.6 \#$ & $163.7 \pm 9.1 \#$ \\
\hline Body mass, kg & $68.5 \pm 9.2$ & $91.7 \pm 12.4$ \#\#\# & $101.1 \pm 12.8^{* * * / \# \# \# ~}$ \\
\hline BMI, $\mathrm{kg} / \mathrm{m}^{2}$ & $23.4 \pm 1.5$ & $32.5 \pm 1.5 \# \# \#$ & $37.5 \pm 1.3 * * * / \# \# \#$ \\
\hline $\mathrm{WC}, \mathrm{cm}$ & $80.2 \pm 6.4$ & $107.3 \pm 8.4$ \#\#\# & $115.7 \pm 7.4 * * * / \# \# \#$ \\
\hline Duration of HBP, years & - & $9 \pm 3$ & $9.5 \pm 3.5$ \\
\hline $\mathrm{SBP}, \mathrm{mm} \mathrm{Hg}$ & $127 \pm 8$ & $161 \pm 12$ \#\#\# & $160 \pm 13$ \#\#\# \\
\hline $\mathrm{DBP}, \mathrm{mm} \mathrm{Hg}$ & $81 \pm 5$ & $100 \pm 6 \# \# \#$ & $99 \pm 6 \# \# \#$ \\
\hline $\mathrm{HBP}^{\circ}{ }^{\circ} / \mathrm{HBP} \mathrm{II}^{\circ}, \%$ & - & $32.6 / 67.4$ & $34.0 / 64.0$ \\
\hline LVMI, $\mathrm{g} / \mathrm{m}^{2.7}$ & $42.06 \pm 7.74$ & $59.28 \pm 14.87 \# \# \#$ & $71.54 \pm 15.73 * * * / \# \# \#$ \\
\hline $\mathrm{TC}, \mathrm{mg} / \mathrm{dl}$ & $194.7 \pm 17.5$ & $230.0 \pm 35.8$ \#\#\# & $235.4 \pm 44.9$ \#\#\# \\
\hline HDL cholesterol, mg/dl & $59.4 \pm 7.9$ & $54.6 \pm 12.8 \#$ & $53.7 \pm 12.7 \#$ \\
\hline LDL cholesterol, mg/dl & $130.2 \pm 34.5$ & $134.6 \pm 34.2$ & $144.4 \pm 44.1$ \\
\hline Triglycerides, mg/dl & $105.7 \pm 23.7$ & $193.5 \pm 74.7$ \#\#\# & $185.3 \pm 64.1 \# \# \#$ \\
\hline Uric acid, mg/dl & $4.74 \pm 1.52$ & $5.96 \pm 1.56 \# \# \#$ & $5.85 \pm 1.39 \# \# \#$ \\
\hline $\mathrm{FPG}, \mathrm{mg} / \mathrm{dl}$ & $90.8 \pm 5.5$ & $103.1 \pm 11.7$ \#\#\# & $101.2 \pm 12.1$ \#\#\# \\
\hline Insulin, $\mu \mathrm{U} / \mathrm{ml}$ & $11.65 \pm 2.78$ & $23.12 \pm 7.31$ \#\#\# & $25.02 \pm 5.78 \# \# \#$ \\
\hline HOMA-IR & $2.82 \pm 0.76$ & $6.78 \pm 1.88 \# \# \#$ & $6.79 \pm 1.74 \# \# \#$ \\
\hline hs-CRP, mg/l & $1.16 \pm 0.82$ & $3.08 \pm 2.09 \# \# \#$ & $4.13 \pm 2.42 * * / \# \# \#$ \\
\hline $\mathrm{T}-\mathrm{Ghr}, \mathrm{pg} / \mathrm{ml}$ & $784.0 \pm 152.6$ & $524.8 \pm 139.4$ \#\#\# & $506.9 \pm 163.0 \# \# \#$ \\
\hline A-Ghr, pg/ml & $165.4 \pm 53.6$ & $161.7 \pm 58.3$ & $143.0 \pm 60.7$ \\
\hline NA-Ghr, pg/ml & $624.6 \pm 140.4$ & $383.1 \pm 137.9$ \#\#\# & $343.8 \pm 133.5$ \#\#\# \\
\hline A-Ghr/NA-Ghr ratio, \% & $27 \pm 11$ & $43 \pm 27 \# \#$ & $55 \pm 28 * / \# \# \#$ \\
\hline PYY 3-36, pg/ml & $108.3 \pm 25.5$ & $92.4 \pm 26.4 \# \#$ & $93.3 \pm 23.7 \# \#$ \\
\hline
\end{tabular}

$\mathrm{WC}=$ Waist circumference; $\mathrm{HBP}=$ hypertension $; \mathrm{DBP}=$ diastolic blood pressure $; \mathrm{SBP}=$ sysstolic blood pressure; $\mathrm{LVMI}=$ left ventricular mass index $\left(\right.$ height $\left.{ }^{2.7}\right) ; \mathrm{TC}=$ total cholesterol; $\mathrm{HDL}=$ high density lipoprotein; $\mathrm{LDL}=$ low density lipoprotein; $\mathrm{FPG}$ = fasting plasma glucose; HOMA-IR = homeostasis model assessment; hs-CRP = highly specific C-reactive protein; $\mathrm{T}-\mathrm{Ghr}=$ total ghrelin; $\mathrm{A}-\mathrm{Ghr}=$ acylated ghrelin; NA-Ghr = nonacylated ghrelin;

A-Ghr/NA-Ghr ratio = acylated/nonacylated ghrelin ratio; PYY 3-36 = peptide YY 3-36,

${ }^{a}$ Data are expressed as means $\pm \mathrm{SD}$.

Lean $=$ BMI $<25.0 \mathrm{~kg} / \mathrm{m}^{2}$ versus obese $=$ BMI $30.0-34.9 \mathrm{~kg} / \mathrm{m}^{2}$ and obese $=$ BMI $35.0-39.9 \mathrm{~kg} / \mathrm{m}^{2}$ : $\# \mathrm{p}<0.05, \# \# \mathrm{p}<0.01, \# \# \mathrm{p}<0.001$.

Obese $=$ BMI $30.0-34.9 \mathrm{~kg} / \mathrm{m}^{2}$ versus obese $=$ BMI $35.0-39.9 \mathrm{~kg} / \mathrm{m}^{2}: * \mathrm{p}<0.05, * * \mathrm{p}<0.01$, $* * * \mathrm{p}<0.001$.
$15 \%$, respectively. NA-Ghr values were calculated as the difference between T-Ghr and A-Ghr values. Also insulin was quantified by the RIA method (Linco Research), intra- and inter-assay coefficients of variations were $4.5 \%$ and $5 \%$, respectively. Insulin resistance (IR) was determined by a homeostasis model assessment HOMA-IR. The scores were calculated by multiplying the product of the fasting serum insulin concentration (mU/l) and the fasting serum glucose concentration $(\mathrm{mmol} / \mathrm{l})$ and then dividing the result by 22.5. The cut-off point of HOMA-IR for patients, defined as mean value $\pm 2 \mathrm{SD}$ of controls, is 3.0. Low-density lipoprotein (LDL) cholesterol was calculated by the Friedewald formula.

\section{Echocardiographic Measurements}

Echocardiographic examinations were made using 2D, M-mode, pulse wave Doppler with $2.5 \mathrm{MHz}$ transducer, according to the recommendations of the American Society of Echocardiography. The measurements included: linear measurements of the left ventricular cavity in diastole left ventricular end-diastolic diameter (LVEDD) and systole left ventricular end-systolic diameter (LVESD), interventricular septum thickness (IVST) and left posterior wall thickness (LPWT). Left ventricular mass
(LVM) was estimated using the formula of Devereux et al. [25, 27]: LVM $=0.8(1.04 \times($ IVST + LVEDD + LPWT $) \times 3-$ LVEDD $\times 3)+0.6$. LVM was normalized by using left ventricular mass index (LVMI) which was calculated as follows: $\mathrm{LVMI}=\mathrm{LVM} / \mathrm{height}^{2.7}$. The presence of left ventricular hypertrophy was diagnosed according to a sex-specific cut-off value. LVMI more than $49.2 \mathrm{~g} / \mathrm{m}^{2.7}$ for men and more than $46.7 \mathrm{~g} / \mathrm{m}^{2.7}$ for women [28-30].

\section{Statistical Analysis}

All statistical analyses were performed using Statistica PL 6.0 software. Data are presented as mean $\pm \mathrm{SD}$. The distribution were checked using Kolmogorov-Smirnov test. The nonparametric tests Mann-Whitney and ANOVA Kruskal-Wallis were used to check for differences between variables. $\log _{10}$ transformation of studied parameters were performed to reduce skewness in the distribution of these variables. Spearman's correlation coefficients were computed to quantify the relationship between variables. Multiple regression analyses were performed to quantify the contribution of independent variables to the variation of left ventricular hypertrophy. p values $<0.05$ were considered statistically significant. 
Table 2. Spearman's correlation coefficients of the relation between different variables within the entire study population

\begin{tabular}{|c|c|c|c|c|c|}
\hline & T.Ghr & A-Ghr & NA-Ghr & A-Ghr/NA-Ghr ratio & PYY 3-36 \\
\hline \multicolumn{6}{|l|}{ BMI } \\
\hline $30.0-39.9, \mathrm{n}=96$ & -0.10 & 0.15 & -0.16 & $0.23, p=0.041$ & 0.04 \\
\hline $30.0-34.9, \mathrm{n}=43$ & 0.05 & 0.11 & 0.01 & 0.14 & -0.06 \\
\hline $35.0-39.9, \mathrm{n}=53$ & -0.21 & -0.11 & -0.18 & 0.05 & 0.16 \\
\hline Lean, $\mathrm{n}=46$ & -0.11 & 0.04 & -0.10 & 0.10 & -0.16 \\
\hline \multicolumn{6}{|l|}{ Insulin } \\
\hline $30.0-39.9, \mathrm{n}=96$ & $-0.31, p=0.0025$ & 0.02 & $-0.36, p=0.001$ & $0.3, p=0.0045$ & -0.02 \\
\hline $30.0-34.9, \mathrm{n}=43$ & $-0.39, \mathrm{p}=0.0608$ & 0.04 & $-0.41, p=0.0068$ & 0.27 & 0.05 \\
\hline $35.0-39.9, \mathrm{n}=53$ & -0.20 & -0.01 & -0.22 & 0.13 & -0.12 \\
\hline Lean, $\mathrm{n}=46$ & -0.02 & -0.09 & -0.02 & -0.02 & -0.14 \\
\hline \multicolumn{6}{|l|}{ HOMA-IR } \\
\hline BMI 30.0-39.9, $\mathrm{n}=96$ & $-0.43, p=0.001$ & $-0.32 p=0.0359$ & $-0.35, p=0.001$ & 0.07 & -0.13 \\
\hline BMI $30.0-34.9, \mathrm{n}=43$ & $-0.45, \mathrm{p}=0.0025$ & -0.29 & $-0.33, p=0.0324$ & -0.05 & -0.18 \\
\hline BMI $35.0-39.9, \mathrm{n}=53$ & $-0.41, p=0.0024$ & -0.26 & $-0.33, p=0.0243$ & -0.01 & -0.14 \\
\hline Lean, $\mathrm{n}=46$ & -0.19 & -0.18 & -0.13 & -0.17 & -0.20 \\
\hline HOMA-IR $<3, \mathrm{n}=14$ & -0.33 & 0.38 & -0.32 & 0.16 & -0.02 \\
\hline HOMA-IR $\geq 3, \mathrm{n}=82$ & $-0.34, p=0.0015$ & -0.17 & $-0.28, p=0.0116$ & 0.05 & -0.08 \\
\hline LVMI (obese) $\mathrm{n}=79$ & $-0.49, \mathrm{p}=0.0001$ & -0.11 & $-0.47, p=0.0001$ & $0.30, p=0.0003$ & $-0.18, p=0.029$ \\
\hline LVMI (lean) n = 46 & -0.12 & -0.23 & -0.03 & -0.15 & -0.04 \\
\hline
\end{tabular}

\section{Results}

Clinical and biochemical characteristics of the hypertensive obese subjects and the healthy lean normotensive subjects are presented in table 1. Compared to healthy controls, both hypertensive obese patient groups had significantly higher values of BMI, WC, SBP and DBP, LVMI, total cholesterol, triglycerides, HDL cholesterol, uric acid, fasting glucose and insulin, hs-CRP levels, and HOMA-IR. Mean body mass, waist circumference, BMI, LVMI, and hs-CRP values were remarkably higher in the more obese patients compared to the less obese. Subgroup analysis revealed significantly lower T-Ghr, NA-Ghr, and PYY 3-36 levels as well as significantly higher values of the A-Ghr/NA-Ghr ratio compared to healthy subjects. We did not document any differences of T-Ghr, A-Ghr, NA-Ghr, and PYY 3-36 levels as well as A-Ghr/NA-Ghr ratio between hypertensive patients in both the more and the less obese subgroups.

We found significant differences between T-Ghr (482.1 \pm 140.6 vs. $547.8 \pm 135.1 \mathrm{pg} / \mathrm{ml} ; \mathrm{p}=0.0034)$, A-Ghr $(135.2 \pm 53.4$ vs. $171.8 \pm 61.6 \mathrm{pg} / \mathrm{ml} ; \mathrm{p}=0.0047)$ in men and women. There was no difference for PYY 3-36.

Of the 96 hypertensive obese subjects, 14 (14.6\%) were identified as having HOMA-IR below the cut-off value of our controls. Comparing obese $\left(\mathrm{BMI}=30.0-39.9 \mathrm{~kg} / \mathrm{m}^{2}\right)$ subjects with HOMA-IR below $3.0(\mathrm{n}=14)$ to subjects with HOMA-IR above $3.0(\mathrm{n}=82)$, we documented significantly higher levels of T-Ghr (613.3 \pm 136.2 vs. $498.1 \pm 135.6 \mathrm{pg} / \mathrm{ml}$; $\mathrm{p}=0.00435)$, A-Ghr $(177.2 \pm 52.4$ vs. $149.4 \pm 60.8 \mathrm{pg} / \mathrm{ml}$; $\mathrm{p}=0.049)$, and NA-Ghr (436.1 \pm 144.2 vs. $348.7 \pm 131.5 \mathrm{pg} / \mathrm{ml}$; $\mathrm{p}=0.034)$. T-Ghr and NA-Ghr were significantly higher and the A-Ghr/NA-Ghr ratio lower in obese $(\mathrm{BMI}=35.0-39.0$ $\left.\mathrm{kg} / \mathrm{m}^{2}\right)$ subjects with HOMA-IR below $3.0(\mathrm{n}=8)$ than in those with HOMA-IR above $3.0(\mathrm{n}=45)(638.5 \pm 131.5$ vs. $483.5 \pm 133.3 \mathrm{pg} / \mathrm{ml}, \mathrm{p}=0.0027 ; 457.0 \pm 159.5$ vs. $323.7 \pm 119.5$ $\mathrm{pg} / \mathrm{ml}, \mathrm{p}=0.044 ; 43 \pm 28$ vs. $56 \pm 29, \mathrm{p}=0.016)$. There were no significant differences in the other obese subgroup (BMI = 30.0-34.9 kg/m²). For PYY 3-36, no significant differences were found in our study population.

Of the 96 hypertensive obese patients, 32 (33.3\%) had hypertension grade $1\left(\mathrm{HBP} \mathrm{I}^{0}\right)$. The analysis did not demonstrate any differences in the mean values of T-Ghr, A-Ghr, NA-Ghr, and PYY 3-36 levels as well as the A/NA-Ghr ratio between obese $\left(\mathrm{BMI}=30.0-39.9 \mathrm{~kg} / \mathrm{m}^{2}\right)$ patients with $\mathrm{HBP}$ $\mathrm{I}^{0}$ and those with HBP $\mathrm{II}^{0}$. However, there were differences in the levels of T-Ghr depending on the severity of hypertension among the patients in both obese subgroups, BMI $=30.0$ $34.9 \mathrm{~kg} / \mathrm{m}^{2}$ and $\mathrm{BMI}=35.0-39.9 \mathrm{~kg} / \mathrm{m}^{2}(543.7 \pm 147.4 \mathrm{vs} .485 .7 \pm$ $116.3 \mathrm{pg} / \mathrm{ml}, \mathrm{p}=0.027$ and $559.1 \pm 164.4$ vs. $480.0 \pm 125.1 \mathrm{pg} / \mathrm{ml}$, $\mathrm{p}=0.012$ ), i.e. the level of T-Ghr was lower in subjects with HPB II ${ }^{0}$. The A-Ghr/NA-Ghr ratio was higher in most obese subjects $(43 \pm 29$ vs. $55 \pm 26 ; \mathrm{p}=0.44)$ whereas the NA-Ghr level in this group was significantly lower $(401.1 \pm 149.8$ vs. $320.4 \pm 106.2 \mathrm{pg} / \mathrm{ml} ; \mathrm{p}=0.028$ ).

Of the 96 hypertensive obese patients, 79 (82.3\%) had left ventricular hypertrophy. As expected, LVMI was higher in the patients with HPB $\mathrm{II}^{0}$ compared to the patients with HPB $\mathrm{I}^{0}\left(72.4 \pm 12.3\right.$ vs. $\left.57.5 \pm 11.2 \mathrm{~g} / \mathrm{m}^{2.7} ; \mathrm{p}=0.012\right)$.

Results of univariate regression analyses between ghrelin forms, PYY 3-36 or A-Ghr/NA-Ghr ratio and HOMA-IR, insulin, and LVMI are summarized in table 2. 
BMI correlated positively with A-Ghr/NA-Ghr ratio in obese subjects $\left(\mathrm{BMI}=30.0-39.9 \mathrm{~kg} / \mathrm{m}^{2}\right)$. In these subjects, also insulin correlated positively with A-Ghr/NA-Ghr ratio, but negatively with T-Ghr and NA-Ghr. Moreover, we found negative associations of HOMA-IR with T-Ghr, A-Ghr, and NAGhr in the moderately obese subgroup $\left(\mathrm{BMI}=30.0-39.9 \mathrm{~kg} / \mathrm{m}^{2}\right)$ as well as with T-Ghr and NA-Ghr in both obese subgroups. In addition, LVMI correlated negatively with T-Ghr, NA-Ghr, and PYY 3-36, while positively with A-Ghr/NA-Ghr ratio. Multiple regression analyses revealed a relationship between LVMI, BMI, HOMA-IR and T-Ghr as follows: $\mathrm{R}=0.49542248$, $\mathrm{R}^{2}=0.24544343, \mathrm{R}^{\wedge 2}=0.22083833, \mathrm{~F}(3.92)=9.9753, \mathrm{p}<0.00001$, $\mathrm{ESE}=14.524, \mathrm{n}=96 . \mathrm{LVMI}=4.14 \pm 21.26+(-3.88 \pm 0.92)$ HOMA-IR $+(-0.04 \pm 0.01) \mathrm{T}-\mathrm{Ghr}+(1.65 \pm 0.53) \mathrm{BMI}+14.52$.

\section{Discussion}

Possible associations between circulating ghrelin and left ventricular hypertrophy or hypertension in obesity have been found in some but not all studies. Öner-Iyidogan et al. [ 31] did not find any differences between ghrelin levels when comparing hypertensive with normotensive obese women. These data demonstrated a positive correlation between T-Ghr and blood pressure and also higher ghrelin levels in hypertensive women with $\mathrm{BMI}<35 \mathrm{~kg} / \mathrm{m}^{2}$. In contrast, two other studies $[24,32]$ reported lower ghrelin levels to be associated with higher blood pressure levels. A further study [33] showed that ghrelin infusion leads to the decrease of blood pressure in healthy volunteers. With regard to ghrelin physiology it could be speculated that the increase in circulating ghrelin levels may be compensatory to the increasing blood pressure. Given that our subjects have suppression of ghrelin levels, it is possible that a loss of ghrelin-mediated control mechanism is present in these cases. Furthermore, lower ghrelin levels have been suggested as participating in dysregulation of endothelial nitric formation which contributes to development of high blood pressure $[19,20]$. Recent research has focused on the association between both forms of ghrelin and the risk of hypertension. The antiinflammatory properties of ghrelin are well known, just as its indirect effect in preventing the development of hypertension in patients with metabolic syndrome [34]. Unfortunately, we were not able to show a positive relationship between the concentration of A-Ghr and SBP, DBP or left ventricular hypertrophy. In contrast, we found negative associations between both forms of ghrelin and LVMI. Nevertheless, in our previous study [9] we reported, for the first time, higher postprandial levels of A-Ghr in extremely obese women with metabolic syndrome as recently suggested Rodriguez et al. [34]. On the other hand, when we analyzed the A-Ghr/NA-Ghr ratio, statistically significant changes were found for increased BMI and hypertension. Additionally, we could confirm that higher hypertension or insulin resistance is associated with lower T-Ghr levels [25, 34-36].
Supporting the relevance of the ghrelin pathway regarding the risk of hypertension, Berthold et al. [35] showed that single nucleotide polymorphisms and haplotypes of the ghrelin gene may be associated with hypertension and atherosclerosis. Furthermore, other studies reported that ghrelin Arg$51 \mathrm{Gln}$ mutation leading to alterations in ghrelin lowers its levels and it is concomitantly associated with the risk of hypertension, impaired glucose levels or type 2 diabetes mellitus $[23,24,37]$. It is interesting that most available data indicate a negative relationship between T-Ghr and insulin levels, insulin resistance or BMI in obese subjects with metabolic syndrome [9, 21, 25, 24, 37]. Interestingly, Rodriguez et al. [34] demonstrated lower NA-Ghr and higher A-Ghr concentrations in patients with metabolic syndrome. With increasing number of the dysfunctions contributing to the metabolic syndrome , a progressive elevation of A-Ghr in plasma and a decrease in plasma NA-Ghr were observed. In addition, $84 \%$ of our study subjects were identified as having insulin resistance which is twice as high as the frequency reported by Rodriguez et al. [34]. In our subjects, T-Ghr was lower in insulin-resistant than in insulin-sensitive subjects. Insulin is believed to have negative impact on ghrelin secretion [20]. In contrast to Rodriguez et al. [34], in our patients A-Ghr was similar among studied subgroups (insulin-resistant vs. insulin-sensitive subjects, HPB $\mathrm{I}^{0}$ vs. HPB $\mathrm{II}^{0}$ subjects as well as more obese vs. less obese subjects). We also observed a strong negative correlation between the two forms of ghrelin, NA-Ghr and A-Ghr, and insulin, HOMA-IR or LVMI. From the multiple regression analyses it could also be concluded that in the accepted model the examined parameters BMI, HOMA-IR, and T-Ghr have independent influence on LVMI, explaining $24 \%$ (total $R^{2} \times 100$ ) variance of this variableWith respect to insulin resistance, the relevance of A-Ghr versus NA-Ghr has been evaluated in two studies [38, 39]. Barrazoni et al. [38] reported that plasma insulin and HOMA-IR were negatively associated with T-Ghr or NAGhr, but positively with A-Ghr and the A-Ghr/NA-Ghr ratio in adults, whereas Pacifico et al. [39] noticed lower T-Ghr and NA-Ghr, comparable A-Ghr, and higher A-Ghr/NAGhr ratio in obese metabolically abnormal children when compared with obese metabolically normal children. These results are in agreement with our observations. As reported previously, obese subjects had increased circulating concentrations of A-Ghr and decreased circulating concentrations of NA-Ghr [34].

Our results also provide a new insight into the understanding of the A-Ghr/NA-Ghr ratio as a clinical biomarker in metabolic disorders. We have noticed, for the first time, that the A-Ghr/NA-Ghr ratio may be relevant in evaluation of HPB $\mathrm{II}^{0}$ ension in patients with BMI between 35.0 and $39.9 \mathrm{~kg} / \mathrm{m}^{2}$. Factors regulating circulating A-Ghr levels are largely unknown. Our previous study demonstrated paradoxically higher levels of A-Ghr under postprandial conditions in extremely obese women. Moreover, A-Ghr consti- 
tuted about $30 \%$ of total ghrelin. Considering the metabolic features associated with A-Ghr in extremely obese subjects, A-Ghr was positively correlated with the percentage of fat mass and also with CRP levels, but negatively with LDL cholesterol and HDL cholesterol [9]. Among many other functions, A-Ghr has beneficial metabolic effects by participating in lipid metabolism over at least two mechanisms. Active ghrelin co-purifies with HDL, destroys lipid peroxides on LDL and may down-regulate CD36 scavenger macrophage receptors [40, 41].

PYY 3-36 belongs to the PP family of 36 amino acid peptides co-released with GLP-1 from endocrine intestinal L cells in response to caloric load. The micronutrient potency of lipids is greater than that of carbohydrates. As shown in this study and a previous study [9], fasting levels of PYY 3-36 were significantly reduced in obese patients compared to lean controls. PYY 3-36, a most potent endogenous Y2R agonist, may modulate action via $\mathrm{Y} 2 \mathrm{R}$. Tests conducted on animals showed that $\mathrm{Y} 2 \mathrm{R}$ appears in arteries of spontaneously hypertensive rats [42]. The activation of this receptor may result in vasoconstrictor effects, suggesting that PYY 3-36 plays a role in the regulation of blood pressure. Boey et al. [43] demonstrated that PYY 3-36 augmented insulin activity. Taking into account metabolic effects in the empirical model of PYY 3-36 participation in insulin sensitivity, it can be assumed that low PYY 3-36 levels in obese subjects may partly contribute to their insulin resistance [43]. Finally, in the present study we found a relationship between PYY 3-36 and LVMI. Nevertheless, we suggest that postprandial profiles of this gut hormone are more relevant in pathological conditions [44].
Given the importance of visceral fat distribution as a risk factor for cardiovascular diseases, the distribution of central obesity in our patients was studied using WC values. As expected, the patients with higher WC and hs-CRP levels had significantly higher LVMI, what is predisposing to left ventricular hypertrophy. We found no correlation of hs-CRP with BMI, WC or LVMI, and we could not confirm prior data reported by Malavazos et al. [45]. In hypertensive younger women with visceral obesity, they found that proinflammatory molecules such as IL-6/IL-6R were significantly associated with echographic abnormalities. IL-6 is a key factor influencing liver-derived CRP [46]. CRP reduces production of NO, the main vasodilator factor [47].

It is also worth emphasizing that uric acid concentrations were higher in our patients. There are few mechanisms leading to higher circulating levels of this factor; hyperinsulinemia, obesity, and antihypertensive drugs such as diuretics, beta-blockers or ACE may be potentially responsible for impaired clearance of uric acid.

Taken together, normalization of circulating gut peptides as well as improvement of impaired insulin sensitivity by weight reduction and diet or surgical procedures might be used in future to normalize hypertension, reduce obesity, and prevent progression of ventricular mass and other cardiovascular events.

\section{Disclosure Statement}

The authors declare no conflicts of interest.

\section{References}

1 Meigs JB: Definitions and mechanisms of the metabolic syndrome. Curr Opin Endocrinol Diabetes 2006;13:103-110.

2 de Simone G, Devereux RB, Chinali M, Roman MJ, Lee ET, Resnick HE, Howard BV: Metabolic syndrome and left ventricular hypertrophy in the prediction of cardiovascular events: the Strong Heart Study. Nutr Metab Cardiovasc Dis 2009;17: 294-302.

3 Iacobellis G, Ribaudo MC, Zappaterreno A, Iannucci CV, Di Mario U, Leonetti F: Adapted changes in left ventricular structure and function in severe uncomplicated obesity. Obes Res 2004;12: $1616-1621$.

4 Devereux RB, de Simone G, Ganau A, Roman MJ: Left ventricular hypertrophy and geometric remodeling in hypertension: stimuli, functional consequences and prognostic implications. J Hypertens Suppl 1994;12:S117-127.

5 Devereux RB, Savage DD, Sachs I, Laragh JH: Relation of hemodynamic load to left ventricular hypertrophy and performance in hypertension. Am J Cardiol 1983;51:171-176.

6 Kojima M, Hosoda H, Date Y, Nakazato M, Kangawa $\mathrm{K}$ : Ghrelin is a growth-hormone-releasing acylated peptide from stomach. Nature 1999;402: 656-660.
7 Soares JB, Leite-Moreira AF: Ghrelin, des-acyl ghrelin and obestatin: three pieces of the same puzzle. Peptides 2008;29:1255-1270.

$\checkmark 8$ Adrain TE, Ferri GL, Bacarese-Hamilton AJ, Fuessl HS, Polak JM, Bloom SR: Human distribution and release of a putative new gut hormone, peptide YY. Gastroenterology 1985;89:1070-1077.

-9 Zwirska-Korczala K, Konturek SJ, Sodowski M, Wylezol M, Kuka D, Sowa P, Adamczyk-Sowa M, Kukla M, Berdowska A, Rehfeld JF, Bielanski W: Basal and postprandial plasma levels of PYY, ghrelin, cholecystokinin, gastrin, and insulin in women with moderate and morbid obesity and metabolic syndrome. J Physiol Pharmacol 2007;58(suppl 1): 13-35.

10 Nagaya N, Miyatake K, Uematsu M, Oya H, Shimizu W, Hosoda H, Kojima M, Nakanishi N, Mori H, Kangawa K: Hemodynamic, renal and hormonal effects of ghrelin infusion in patients with chronic heart failure. J Clin Endocrinol Metab 2001;86:5854-5859.

11 Shinde UA, Desai KM, Yu C, Gopalakrishnan V: Nitric oxide synthase inhibition exaggerates the hypotensive response to ghrelin: role of calciumactivated potassium channels. J Hypertens 2005;23: 779-784.
12 Adrain TE, Sagor GR, Savage AP, Bacarese-Hamilton AJ, Hall GM, Bloom SR: Peptide YY kinetics and effects on blood pressure and circulating pancreatic and gastrointestinal hormones and metabolites in man. J Clin Endocrinol Metab 1986;63:803807.

13 Wiley KE, Davenport AP: Comparison of vasodilatators in human internal mammary artery: ghrelin is a potent physiological antagonist of endothelin-1. Br J Pharmacol 2002;136:1146-1150.

14 Tesauro M, Schinzari F, Rovella V, Di Daniele N, Lauro D, Mores N, Veneziani A, Cardillo C: Ghrelin restores the endothelin-1/nitric oxide balance in patient with obesity-related metabolic syndrome. Hypertension 2009;54:995-1000.

15 Dixit VD, Taub DD: Ghrelin and immunity: a young player in an old field. Exp Gerontol 2005; 40:900-910.

16 YadaT, Kaija H, Mutoh K, Azuma T, Hyodo S, Kangawa K: Ghrelin stimulates phagocytosis and superoxide production in fish leukocytes. J Endocrinol 2006;189:57-65.

17 Zhang M, Yuan F, Chen H, Qiu X, Fang W: Effect of endogenous ghrelin on cell differentiation antigen 40 expression in endothelial cells. Acta Biochim Biophys Sin 2007;39:974-981. 
18 Kawczynska-Dro d A, Olszanecki R, Jawien J, Brzozowski T, Pawlik WW, Korbut R, Guzik TJ: Ghrelin inhibits vascular superoxide production in spontaneously hypertensive rats. Am J Hypertens 2006;19:764-767.

19 Widlansky ME, Gokce N, Keaney JF Jr, Vita JA The clinical implication of endothelial dysfunction. J Am Coll Cardiol 2003;42:1149-1160.

20 Iantorno M, Chen H, Kim J, Tesauro M, Lauro D, Cardillo C, Quon M: Ghrelin has novel vascular actions that mimic PI 3-kinase-dependent actions of insulin to stimulate production of NO from endothelial cells. Am J Physiol Endocrinol Metab 2007;292:E756-E764.

21 Tschöp M, Weyer C, Tarannini PA Devanarayan V, Ravussin E, Heiman ML: Circulating ghrelin levels are decreased in human obesity. Diabetes 2001;50:707-709.

22 Korbonitis M, Goldstone AP, Gueorguiev M, Grossman AB: Ghrelin - a hormone with multiple function. Front Neuroendocrinol 2004:25:27-68.

-23 Pöykkö SM, Ukkola O, Kauma H, Savolainen MJ, Kesaniemi YA: Ghrelin Arg51Gln mutation is a risk factor for type 2 diabetes and hypertension in a random sample of middle-age subjects. Diabetologia 2003;46:455-458.

24 Poykko SM, Kellokoski E, Horkko S, Kesaniemi YA, Ukkola O: Low plasma ghrelin is associated with insulin resistance, hypertention, and the prevalence of type 2 diabetes. Diabetes 2003;52:25462553.

25 Ukkola O, Pöykkö SM, Kesaniemi YA: Low plasma ghrelin concentration is an indicator of the metabolic syndrome. Ann Med 2006;38:274-279.

26 Mancia G, de Backer G, Dominiczak A, Cifkova R, Fagard R, Germano G, Grassi G, Heagerty AM, Kjeldsen SE, Laurent S, Narkiewicz K, Ruilope L, Rynkiewicz A, Schmieder RE, Boudier HA, Zanchetti A: 2007 Guidelines for the Management of arterial hypertension: the Task Force for the Management of Arterial Hypertension of the European Society of Hypertension (ESH) and of the European Society of Cardiology (ESC). J Hypertens 2007;25:1105-1187.

-27 Devereux RB, Reichek N: Echocardiographic determination of left ventricular mass in man. Anatomic validation of the method. Circulation 1977; 55:613-618.

-28 de Simone G, Devereux RB, Daniels SR, Koren MJ, Meyer RA, Laragh JH: Effect of growth on variability of left ventricular mass: assessment of allometric signals in adults and children and their capacity to predict cardiovascular risk. J Am Coll Cardiol 1995;25:1056-1106.
9 Devereux RB, Pini R, Aurigemma GP, Roman MJ: Measurement of left ventricular mass: methodology and expertise. J Hypertens 1997:15:801-809.

30 Levy D, Anderson KM, Savage DD, Kannel WB, Christiansen JC, Castelli WP:Echoradiographically detected left ventricular hypertrophy: prevalence and risk factors . The Framingham Heart Study. Ann Intern Med 1988;108:7-13.

31 Öner-Iyidogan Y, Kocak H, Gürdöl F. Öner P, Issever H, Esin D: Circulating ghrelin levels in obese women: a possible association with hypertension. Scand J Clin Lab Invest 2007;67:568-576.

32 Fagerberg B, Hulten LM, Hulthe J: Plasma ghrelin, body fat, insulin resistance, and smoking in clinically healthy men: the Atherosclerosis and Insulin Resistance Study. Metabolism 2003;52:1460-1463.

33 Nagaya N, Kogima M, Uematsu M, Yamagishi M, Hosoda H, Oya H, Hayashi Y, Kangawa K: Hemodynamic and hormonal effects of human ghrelin in healthy volunteers. Am J Physiol Regul Integr Comp Physiol 2001;280:R1483-R1487.

34 Rodriguez A, Gomez-Ambrosi J, Calatan Victoria, Becerril S, Sainz N, Jesus Gil, Silva C, Salvador J, Barba J, Colina I, Frühbeck G: Association of plasma acylated ghrelin with blood pressure and left ventricular mass in patients with metabolic syndrome. J Hypertens 2010;28:560-567.

35 Berthold HK, Giannakidou E, Krone W, Tregouet DA, Gouni-Berthold I: Influence of ghrelin gene polimorphisms on hypertension and atherosclerotic disease. Hypertens Res 2010;33:155-160.

36 Langerberg C, Bergstrom J, Laughlin GA, BarrettConnor E: Ghrelin and the metabolic syndrome in older adults. Clin Endocrinol Metabol 2005;90: 6448-6453.

37 Baessler A, Kwitek AE, Fischer M, Koehler M, Reinhard W, Erdmann J, et al: Association of ghrelin receptor gene region with ventricular hypertrophy in the general population: result of the MONICA/KORA Augsburg Echocardiographic Substudy. Hypertension 2006;47:920-927.

38 Barazzoni R, Zanette M, Ferreira C, Vici P, Pirulli A, Mucci M, et al: Relationships between desacylated and acylated ghrelin and insulin sensitivity in the metabolic syndrome. J Clin Endocrinol Metabol 2007;92:3935-3940.

39 Pacifico L, Poggiogalle E, Constantino F, Anania C, Ferraro F, Chiarelli F, Chiesa C: Acylated and nonacylated ghrelin levels and their association with insulin resistance in obese and normal weight children with metabolic syndrome. Eur J Endocrinol 2009;161:861-870.
40 Demers A. McNicoll N, Febbraio M, Servant M, Marleau S, Silerstein R, Ong H: Identification of the growth hormone-releasing peptide binding site in CD36: photoaffinity cross-linking study. Biochem J 2004;382:417-424.

41 Avallone R, Demers A, Rodrique-Way A, Bujold K, Harb D, Anghel S, Wahli W, Marleau S, Ong H, Tremblay A: A growth hormone-releasing peptide that binds scavenger receptor CD36 and ghrelin receptor upregulates $\mathrm{ABC}$ sterol transporters and cholesterol efflux in macrophages trough a peroxisome proliferator-activated receptor gammadependent pathway. Mol Endocrinol 2006;12:31333145 .

42 Gradin KA, Buus CL, Li JY, Frobert O, Simonsen $\mathrm{U}$ : Neuropeptide Y2 receptors are involved in enchanced neurogenic vasoconstriction in spontaneously hypertensive rats. Br J Pharmacol 2006;148: 703-713.

43 Boey D, Heilbronn L, Laybutt DR, Kriketos AD, Herzog H, Campbell LV: Low serum PYY is linked to insulin resistance in first-degree relatives of subjects with type 2 diabetes. Neuropeptides 2006;40:317-324.

44 Zwirska-Korczala K, Sodowski K, Konturek SJ, Kuka D, Kukla M, Brzozowski T, Cnota W, Wozniak-Grygiel E, Jaworek J, Buldak R, RybusKalinowska B, Fryczkowski M: Postprandial response of ghrelin and PYY and indices of lowgrade chronic inflammation in lean young women with polycystic ovary syndrome. J Physiol Pharmacol 2008;59(suppl 2):161-178.

45 Malavazos AE, Corsi MM, Ermetici F, Coman C, Sardanelli F, Rossi A, Morricone L, Ambrosi B: Proinflammatory cytokines and cardiac abnormalities in uncomplicated obesity: relationship with abdominal fat deposition. Nutr Metab Cardiovasc Dis 2007;17:294-302.

46 Florez H, Silva E, Fernandez V, Ryder E, Sulbaran T, Campos G, Calmon G, Clarel E, Castillo-Florez S, Goldberg R: Prevalence and risk factors associated with metabolic syndrome and dyslipidemia White, Black Amerindian and Mixed Hispanic in Zulia State, Venezuela. Diab Res Clin Pract 2005; 71:63-77.

47 Taddei S, Virdis A: Exogenous ghrelin on nitric oxide-endothelin 1 imbalance in metabolic syndrome: can we kill 2 birds with 1 stone? Hypertension 2009;5:960-961. 